Environmental Research Journal 5 (2): 87-92, 2011

ISSN: 1994-5396

(C) Medwell Journals, 2011

\title{
A Review Crop Raiding Around Protected Areas: Nature, Control and Research Gaps
}

\author{
Bernard Fungo \\ Department of Forest Biology and Ecosystems Management, \\ Makerere University, P.O. Box 7062, Kamapala, Uganda
}

\begin{abstract}
Conservation and sustainable use of Protected Areas (PAs) requires concerted effort of both conservation stewards and local communities. Crop raiding is a major constraint to both of them. Farmers loose large amount of their crops to wild animals from the PAs while conservation stewards are challenged by how to win local support for successful conservation efforts to be realized. This contribution reviews literature on nature and extent of crop raiding form some PAs and how local communities and conservation stewards respond to the problem. An assessment of the methods used by various researchers to measure the extent of crop raiding and some recommendation for further research are made.
\end{abstract}

Key words: Crop raiding, measurement, control methods, research gaps, recommendation, Uganda

\section{INTRODUCTION}

Crop raiding around Protected Areas (PAs) is one of the major challenges facing conservation efforts. Conserving the wildlife species is one objective while ensuring local community benefits from the conservation is an important but controversial objective. The impact of crop raiding on attitudes of local communities towards PAs can undermine efforts to gain their support for conservation, even when the programs provide substantial economic benefits.

Archabald and Naughton-Treves (2001) for example, noted that in Uganda, conflict between local communities and managers of Bwindi National park arose because of crop raiding and continued despite local development projects receiving a percentage of the revenue from tourism. Hunting is a traditional method of mitigating crop loss that involves both trapping around fields and killing animals found raiding crops or livestock (Nyhus et al., 2003). Preventing such practices requires approaches that promote reconciliation between protected area managers and communities surrounding protected areas. It is therefore important that managers of protected areas address issues of crop raiding to alleviate conflict with local communities and reduce conservation threats from poaching wild animals. In terms of crop production, crop raiding is a major constraint to local communities for example, in Bwindi, Lake Mburo National park (Infield and Namara, 2001; Kagoro-Rugunda, 2004), Budongo forest reserve (Hill, 1997; Twheyo, 2003) and Kibale National park (Naughton-Treves, 1998; Lwanga, 2006). Previous studies around Bwndi National park have shown that communities consider baboons, monkeys and bush pigs to be responsible for most crop raiding. These animals are reported to raid all major food crops including sorghum, millet and maize. Various small mammals have been observed raiding crops but the level of raiding is considered low in comparison with baboons, L'Hoesti monkeys, blue monkeys, chimpanzees, gorillas and bush pigs. Fields adjacent to protected areas are for example, most affected as the majority of baboon raids occur within $200 \mathrm{~m}$ of the forest edge. In areas where they occur such as Bwindi National Park, wild animals forage within community land.

Crop loss to wild animals is a major problem facing protected area managers such as Uganda Wildlife Authority (UWA) and National Forestry Authority (NFA). From the conservation point of view, the retention of animals in the wild in protected areas plays a key role in maintaining the ecosystem functions and subsequent benefits thereof. From the community's view point however, this means loss of crops and destruction of property and structures (such as houses and fences).

Ironically, maintaining wildlife also introduces the opportunity cost of land that could have been used for agricultural activities and settlement. The aim of this study it to provide a critical review of what we know about crop raiding and identify the knowledge gaps that next-generation research needs to address.

\section{CROP RAIDING ACTIVITIES OF WILD ANIMALS}

Species involved and levels of raiding: Crop raiding by wild animals is caused by several species that range from large mammals such as elephants to smaller ones such as red-tailed monkeys, olive baboons, bush pigs, palm 
civets, chimpanzees, black and white colobus, African civets, crested porcupines, vervet monkeys, brush-tailed monkeys, red duikers, bush backs and rodents (Naughton-Treves, 1998). Hill (1997) found that baboons caused the most raiding to crops in areas around Budongo forest reserve.

They raided farms more frequently than other species of wild animals visiting farmers' field throughout the year and caused greater amounts of raiding than all other animals combined. Compared to other crops, they preferred maize and cassava which were the two most frequently cultivated field crops. Hill (1997) also noted that maize and cassava within the community around Budongo Forest Reserve were destroyed severely and yet they formed the basis of most households' meals. Several studies have attempted to quantify the levels of raiding that wildlife cause to crops (Haule et al., 2002; Kagoro-Rugunda, 2004; Hill, 1997, 2000) for example, Kirstin found that red colobus monkeys fed on immature coconuts but did not significantly affect coconut yield at harvest. On the contrary, Red Colobus consumption of coconuts was found to be positively correlated with harvest. Generally, the nature of raiding depends on the species involved. Raiding by large mammals includes trampling, eating whole leaves of bananas, maize and cassava stems. Smaller animals such as monkeys, baboons, porcupines and bush pigs also raid crops by removing maize cobs, uprooting cassava, sweet potatoes and ground nuts (Struhsaker, 1999). Design of the methods for assessing raiding should consider the animals raiding as well as the nature of crop being raided.

Factors affecting level of crop raiding by wild animals Distance from the boundary: Distance of field boundaries from the forest and other habitats is an important factor in determining the likelihood of incursion by wild animals (Hill, 1997, 2000; Hoare, 1999; Kagoro-Rugunda, 2004; Sitati et al., 2005). In Linkie, farmers reported no crop losses from animals in cultivated fields that were over $300 \mathrm{~m}$ away from the forested areas and plantations. Different wild animal species are commonly associated with different habitat types.

According to Sitati et al. (2005) two aspects of farm location need to be considered: the nearest food habitat from farm boundaries and the distance between habitat types and field boundaries. Other physical factors or guarding measures had no effect on crop raiding incidence (Sitati et al., 2005).

In a field trial, Linkie showed that the spatial patterns of crop raids by pig-tailed macaque raids were not as widespread as those of wild boar, implying that various animals have different extents of raiding. In contrast to situations where animals raid gardens that are far away, the majority of those experiencing crop-raiding have farms within $100 \mathrm{~m}$ from the protected area boundaries. Linkie reported that all farms within $50 \mathrm{~m}$ experienced crop raiding by mammals.

However, farms closest to the forest edge were most frequently raided by wild boar, pig-tailed macaque and porcupine individually and by all species combined. An important point to note here is that it is not just distance per se that is important.

The further away from the forest or plantation edge a given farm is the greater the number of buffering farms there are between that farmland and the forest boundary. Animals are less likely to enter a farm if they have to traverse several other farms to reach it. Sitati et al. (2005) showed that those farmers who do not experience crop-raiding have on average, two other farms between them and any tree habitat.

Crop species grown: The extent of raiding depends on the crop available. There are a number of factors, including the stage at which a crop raided and the diversity of species that will feed on it. Hill (1997) reported that maize is attacked at all stages in its development from the newly sown seed to the time when the cobs are mature. While, raiding sustained at any stage can cause severe crop losses, the most serious time is when a mature crop sustains substantial losses which is potentially the case with maize.

Certain crops such as maize, bananas and passion fruits are favored foods of primate crop raiders while other such as cassava and sweet potatoes are mainly raided by bush pigs and rodents (Sitati et al., 2005). Crops that are less susceptible to raiding include ground nuts, beans and coffee.

Season: Seasonal variation of crop raiding incidence is mostly attributed to forage availability. In a dry season, farms suffered more crop raiding. Rainfall determines the growth of the farm-bush mosaic that is so attractive for example, to elephants (Barnes et al., 2005). It also promotes the growth of maize and it is the maturing maize crop that draws crop raiders (Chiyo et al., 2005). Barnes et al. (2007) correlated rainfall frequency with incidence of elephant raiding and found the former to be an important predictor. Furthermore, on wet nights farmers prefer to sleep at home and consequently crop raiding animals are free to move about under cover of the rain. Clouds obscure the moon so that rainy months are darker and this also explains why rain and the moon together have a significant effect upon elephant movements. According to Dickinson, the moon could influence 
elephant behavior associated with crop raiding. Animals vulnerable to nocturnal predators are more active around the new moon e.g. and elephants feel safer venturing into the fields on moonless nights. Rural people are more likely to stay awake on brightly lit nights and guard dogs are more vigilant. According to Barnes et al. (2005) analysis of radio-tracking data confirm that in other habitats, the nocturnal range of elephants depends on the lunar cycle.

Animal density: Sites with high densities of crop raiders will have higher severities of crop raiding. Kirstin found that the consumption of coconuts was highest in areas of high red colobus density and low availability of alternative food resources. On the contrary, Hoare (1999) showed that incidence of crop raiding by elephants did not correlate positively with local changes in the elephant density.

Although, Protected Areas (PAs) serving as elephant refuges, in the Sebungwe National Park in Zimbabwe, they are known to have almost twice the elephant density of refuges within the Coward neither the type of refuge nor the elephant density within it appeared to determine levels of elephant crop raiding in adjacent gardens (Boulton et al., 1995).

\section{COMMUNITY MEASURES FOR DETERRING CROP RAIDERS}

Local communities have adopted several measures to deter crop raiding wild animals from their gardens. Some of the most common measures include guarding (Hill, 2000), smearing with cow dung, scarecrows, wrapping with cloth (targeting mainly primates), lighting fire at night, trenches against bush pigs (Kagoro-Rugunda, 2004) and fencing (Thouless and Sakwa, 1995).

These methods are used either individually or in combination. Selection of the method to use depends on size of the fields, crop grown, availability of labour to guard and vulnerability of the crop to available raiders. Active methods to scare away crop raiding animals such as burning fires and banging tins and drums, increased farmers ability to prevent raiding. Passive barrier methods such as wooden post and barbed wire fences have been used in several areas.

For example, around Kasohya-Kitomi forest reserve in Bushenyi (Uganda), farmers dig trenches to a depth of one meter so that large animals do not cross to the farms from the forest. In Bwindi and Mgahinga Gorilla National parks, planting of live fences of Ceasalpinia decapetala alongside the park boundary on community land is being carried out in two parishes. However, the communities have been reluctant to maintain it citing the absence of an approved memorandum of understanding as the problem.

For such destructive animals as elephants once within a field there is little that can be done to reduce the raiding caused. The alternative is to plant such barriers that deter them from reaching the gardens. Guarding is reported to be the most effective method and therefore investment in human resources appears to be a significant factor in preventing crop raiding (Hoare, 1999). Sitati et al. (2005) reported that larger farms require more effort to guard for the method to be effective but Kagoro-Rugunda (2004) noted that itwas tiresome and risky in the case of nocturnal animals such as bush pigs.

It led to the disruption of the social life communities. For example, men do not stay in their houses because they have to keep watching their gardens at night, children have shorter school days (Hill, 2000) and women fail to fetch water and firewood.

There has been limited investigation into the effectiveness of the various methods in reducing crop raiding. Sitati et al. (2005) however, showed that passive barrier methods were largely ineffective since animals were easily able to break through them. Barriers are popular with communities because they may be of use against smaller crop pests such as zebra Equus burchelli gray and with donors because they represent a tangible and potentially long-term capital expense.

Barriers alone are more effective if they are electrified and/or totally enclose an area of cultivation (O'Connell-Rodwell et al., 2000; Osborn and Parker, 2002). They however, require significant resources for recurrent maintenance. For most farmers therefore, investment in guarding is likely to be a better option. According to Thouless and Sakwa (1995), comparison of different electric fences showed that there was no clear relationship between effectiveness of fences and factors such as design, construction and voltage.

\section{RESPONSE BY CONSERVATION STEWARDS}

Managers of PAs are increasingly adopting strategies to mitigate the crop raiding activities of wild animals and so improve attitudes to conservation among rural communities neighboring PAs (Osborn and Parker, 2003). The various mitigation methods include scaring animals away from crops, scare-shooting, use of barriers e.g. by planting fields of non-edible crops and trenches. Compensation is also a possible means for managers to address human-wildlife conflict (Balasubramanian et al., 1995; Baker, 2004). The success or otherwise of compensation schemes to reduce local 
costs of crop raiding and the effectiveness of mitigation methods in preventing wild animals from raiding crops (Thouless and Sakwa, 1995; Osborn and Parker, 2002; Osborn and Parker, 2003) have been evaluated. Some studies (Gillingham and Lee, 1999) have examined how mitigation efforts by conservation authorities influence their relations with local communities. In Uganda, rural farmers continued to receive assistance with vermin control until the 1980 s when the operations of the game department were restricted by the civil war. One vermin guard was stationed at Bwindi when the forest was under joint management of the Game and Forest Departments although, staff of both departments regularly assisted farmers by scare-shooting when wild animals foraged within agricultural land. Game guards, in particular would respond when large animals such as elephants, entered community land and the guards would also kill smaller mammals that frequently raided crops and livestock, including baboons and bush pigs. Vermin control remained a duty of the rangers after Bwindi was designated a National park.

Rangers employed scare shooting for elephants and monkeys and chased gorillas and duikers into the forest by shouting and beating drums. Farmers often request assistance when rangers pass their fields while patrolling the National Park boundary and some farmers will travel to the outpost to request assistance. However, problem animal control is a secondary duty for the rangers after law enforcement and the ranger in charge of each outpost will decide on a day to day basis whether or not to assist the farmers. Currently, protected areas where crop raiding is more common (forests and game parks/reserves) are under the National Forestry authority and Uganda Wildlife authority, respectively. Although, evidence of crop raiding exists, no record of compensation is known to researchers.

\section{METHODS OF ASSESSING CROP RAIDING}

Many studies have estimated levels of crop raiding by wild animals. Whereas some rely on farmers estimates (Bell, 1984; Conover and Decker, 1991; Horrocks and Baulu, 1994; Hill, 1997; De Boer and Baquete, 1998; Tweheyo and Obua, 2001; Haule et al., 2002), others have used independent measurements of raiding crops to determine crop raiding levels (Newmark et al., 1993; Naughton-Treves, 1998; Kagoro-Rugunda, 2004; Sitati et al., 2005). The period over which such studies have been conducted also varies tremendously. For example, to determine how crop raiding was distributed throughout the year, Hill (1997) conducted monthly farm visits for 12 months.
Similarly, Naughton-Treves (1998) Kagoro-Rugunda (2004) determined seasonal patterns of raiding by taking either weekly or monthly visits for a period of between 6 months and 2 years. However, no studies on daily patterns of crop raiding have been found in the literature. The methods used to study seasonal patterns may also be useful in determining daily patters. Barnes et al. (2005) determined crop raiding incidents by elephants over a 1 year period by recording, on a monthly basis, the number of elephant raids that occurred on particular farms. The number of raids recorded was typical count data. Measurement of actual crop losses is potentially difficult and controversial. Aside from the problems of collection of data on crop losses there is also the problem of determining what to measure and therefore whether measures of losses are comparable from study to study or site to site. To put crop loss in perspective, it is useful to compare measures of crop raiding but there are some potential problems. Firstly, how accurate do the measurements of crop loss need to be? Hill et al. (2002) concede that it is difficult to collect accurate information and data collection can be rife with sources of error. Secondly, different studies make different measurementssome convert an area of loss to an estimate of $\mathrm{kg} / \mathrm{ha}$ lost (Siex and Struhsaker, 1999).

Others may present the average percent of loss per field (Siex and Struhsaker, 1999; Kagoro-Rugunda, 2004) or the average \% loss per raiding event or even the overall mean annual percentage loss. Within some of the studies that make use of quadrat techniques for sampling crop losses there appears to be the assumption that all areas within a field/crop stand are equally affected. Therefore, any mean percentage loss can be extrapolated to the entire area under that crop. Kagoro-Rugunda (2004) determined the amount of raiding by counting the number of stems of each raided crop type (bananas, maize, cassava, yams) and converting this to per square meters basis using average planting densities for each crop while raiding on sawn crops (such as millet, sorghum) was measured directly in square meters. Musaasizi used a similar method to assess crop raiding by wild pigs around Bwindi Impenetrable National park.

However, case studies have demonstrated that crop raiding wildlife generally travel a certain distance from the PA in their search for crop forage. Thus, it is important to take this into account when extrapolating rates of raiding from one area of a field to another. Otherwise, estimates of crop losses/ha are likely to be unintentionally inflated.

In addition, different farmers have different planting strategies. For instance, Hill et al. (2002) noted that farmers around Budongo forest Reserve, Uganda who, on average have small land holdings, tend to plant $>1$ field of important staple crops in any one growing season. The 
reason given for this is that it reduces the risk of suffering high losses through wildlife, pests and diseases and variable soil fertility (Hill, 2000). This is not an unusual planting strategy for small-scale farmers in tropical regions but is not always apparent that this is taken into account when calculating the percent crops lost-so again losses may be unintentionally inflated.

Where such values are extrapolated to the village, community or district level there needs to be some factoring-in of differential risk across different farms. Measurement of crop loss can also be a problem from the point of view of distribution of compensatory revenue from sources such as PA gate returns. Ugandan farmers are well aware of this and express concern about the fact that any benefits that might accrue from living alongside wildlife (e.g., profits from local community run tourist wildlife viewing facilities) will go to local institutions for the befits of all people yet it is only certain individuals that bear the actual cost of living alongside these animals. Farmers at the forest edge actually buffer their colleagues farming more central regions (Hill, 2000). There are a number of problems with these methods of collecting data (without using additional sources of information to cross check) if one is looking for a way of determining accurately how frequently particular animals visit fields or which animals cause most raiding (Hill et al., 2002). It is important to bear in mind that informants are not necessarily intentionally giving what amounts to false information.

Hill et al. (2002) noted that people's perception and memory can be influenced by a number of different factors and particular events may take on a greater significance in retrospect. Some studies have used farmer estimates of crop losses (Kagoro-Rugunda, 2004), looking at either the amount of crops lost and/or the monetary value of those crop losses. Where these studies have combined this with an independent assessment of crop losses by the researcher (s), farmers tend to overestimate their losses by as much as $30-35 \%$. However, information from farmers and other stakeholders is not necessarily unreliable and inaccurate. Such information as with all data, needs to be handled and interpreted appropriately.

Having accurate, longer term, knowledge of the situation will enable crosschecking of information and add considerably to the value and usefulness of such results. Therefore, reports from communities may be unreliable sources to base on in decisions concerning raiding levels. In fact Infield (1988), Newmark et al. (1993) and reported that farmers' perception of the animals that cause raiding were found to be exceedingly higher that independent assessments. While independent plot assessment showed that raids by wild boars were more extensive than raids by pig-tailed macaques which caused much greater crop raiding $(73 \%)$ than wild boars $(26 \%)$, contrary to farmers perceptions. Sitati et al. (2005) argue that the lack of compensation for wildlife-imposed raiding provides strong incentives for exaggeration of human-wildlife conflicts.

\section{CONCLUSION}

Crop raiding is a real problem faced by farmers around PAs. The several studies attempt to fill gaps in knowledge of the extent of the problem, community perception of the problem and policy options for intervention to reduce crop raiding. However, literature on appropriate methods to assess damage is scanty. Future crop raiding studies should focus on how to translate wildlife crop raiding of various crops into economic loss to the farmers around PAs, including the opportunity cost of control methods. There is also need for studies on the crop yield gap attributable to crop raiding by wild animals.

Since, some socio-economic factors such as farm size, income, alternative economic activities and family size can impinge on farm management practices, an in-depth investigation into the relationship between them yields invaluable information for socio-economic interventions. Additionally, information on the types, relative abundance and spatial distribution of primate foods within the different ecological niches of the PAs and its temporal variability is inexorably important.

\section{REFERENCES}

Archabald, K. and L. Naughton-Treves, 2001. Tourism revenue-sharing around national parks in Western Uganda: Early efforts to identify and reward local communities. Environ. Conserv., 28: 135-149.

Baker, J., 2004. Evaluating conservation policy: Integrated conservation and development in Bwindi impenetrable national park, Uganda. Ph.D. Thesis, Durrell Institute of Conservation and Ecology, University of Kent. Canterbury.

Balasubramanian, M., N. Baskaran, S. Swaminathan and A.A. Desai, 1995. Crop raiding by Asian elephant (Elephas maximus) in the Nilgiri Reserve, South India. A week with Elephants: Proceedings of the International Seminar on the Conservation of the Asian Elephant, (Eds J.C. Daniel and H.S. Datye), June 1993, Oxford University Press, Bombay.

Barnes, F.W., E.M. Hema, A. Nandjui, M. Manford, U.F. Dubiure, E.K.A. Danquah and Y. Boafo, 2005. Risk of crop raiding by elephants around the Kakum conservation area, Ghana. Pachyderm, 39: 19-25.

Barnes, R.F.W., U.F. Dubiure, E. Danquah, Y. Boafo, A. Nandjui, E.M. Hema and M. Manford, 2007. Crop-raiding elephants and the moon. Afr. J. Ecol., 45: 112-115. 
Bell, R.H.V., 1984. The Man-Animal Interface: An Assessment of Crop Raiding and Wildlife Control. In: Conservation and Wildlife Management in Africa, Bell, R.H.V. and E. McShane- Caluzi (Eds.). US Peace Corps, Lilongwe, pp: 387-416.

Boulton, A.M., J.A. Horracks and J. Baulu, 1995. The Barbados vavet monkey (Cercopithecus aethiops sabaeus): Changes in population size and crop raiding 1980-1994. Int. J. Primatol., 17: 831-844.

Chiyo, P.I., E.P. Cochrane, L. Naughton and G.I. Basuta, 2005. Temporal patterns of crop raiding by elephants: A response to changes in forage quality or crop availability? Afr. J. Ecol., 43: 48-55.

Conover, M.R. and D.J. Decker, 1991. Wildlife raiding to crops: Perceptions of agricultural and wildlife professionals in 1957 and 1987. Wildlife Soc. Bull., 19: 46-52.

De Boer, W.F. and D.S. Baquete, 1998. Natural resource use, crop raiding and attitudes of rural people in the vicinity of Maputo Elephant Reserve, Mozambique. Environ. Conserv., 25: 208-218.

Gillingham, S. and P.C. Lee, 1999. The impact of wildliferelated benefits on the conservation attitudes of local people around the Selous Game Reserve, Tanzania. Environ. Conserv., 26: 218-228.

Haule, K.S., F.H. Johnsen and S.L.S. Maganga, 2002. Striving for sustainable wildlife management: The case of Kilombero game controlled area, Tanzania. J. Environ. Manage., 66: 31-42.

Hill, C., F. Osborn and A.J. Plumptre, 2002. Human-wildlife conflict: Identifying the problem and possible solutions. Albertine Rift Technical Report Series Vol. 1. Wildlife Conservation Society.

Hill, C.M., 1997. Crop raiding by wild veterbrates: The farmers perspective in an agricultural community in western Uganda. Int. J. Pest Manage., 43: 77-84.

Hill, C.M., 2000. Conflict of interest between people and baboons: Crop raiding in Uganda. Int. J. Primatol., 21: 299-315.

Hoare, R.E., 1999. Determinants of human-elephant conflict in a landuse mosaic. J. Applied Ecol., 36: 689-700.

Horrocks, J. and J. Baulu, 1994. Food competition between vervets (Cercopithecus aethiops sabaeus) and farmers in Barbados: Implications for management. Rev. Ecol., 49: 281-294.

Infield, M. and A. Namara, 2001. Community attitudes and behavior towards conservation: An assessment of a community conservation program around Lake Mburo National Park, Uganda. Oryx, 35: 48-60.

Infield, M., 1988. Attitudes of a rural community towards conservation and a local conservation area in Natal: South Africa. Biol. Conserv., 45: 21-46.
Kagoro-Rugunda, G., 2004. Crop raiding around Lake Mburo National Park, Uganda. Afr. J. Ecol., 42: 32-41.

Lwanga, J.S., 2006. The influence of forest variation and possible effects of poaching on duiker abundance at Ngogo, Kibale National Park, Uganda. Afr. J. Ecol., 44: 209-218.

Naughton-Treves, L., 1998. Predicting patterns of crop raiding by wildlife around Kibale National Park, Uganda. Conserv. Biol., 12: 156-168.

Newmark, W.D., N.L. Leonard, H.I. Sariko and D.M. Gamasa, 1993. Conservation attitudes of local people living adjacent to five protected areas in Tanzania. Biol. Conserv., 63: 177-183.

Nyhus, P., H. Fische, F. Madden and S. Osofsky, 2003. Taking the bite out of wildlife raiding-the challenges of wildlife compensation schemes. Springer, 4: 1-7.

O'Connell-Rodwell, C.E., T. Rodwell, M. Rice and L.A. Hart, 2000. Living with the modern conservation paradigm: can agricultural communities co-exist with elephants? A five-year case study in East Caprivi, Namibia. Biol. Conserv., 93: 381-391.

Osborn, F.V. and G.E. Parker, 2002. Community-based methods to reduce crop loss to elephantsexperiments in the communal lands of Zimbabwe. Perchyderm, 33: 32-38.

Osborn, F.V. and G.E. Parker, 2003. Towards an integrated approach for reducing the conflict between elephants and people: A review of current research. Oryx, 37: 80-84.

Siex, K.S. and T.T. Struhsaker, 1999. Colubus monkeys and coconuts: a study of perceived human-wildlife conflicts. J. Applied Ecol., 36: 1009-1020.

Sitati, N.W., M.J. Walpole and N. Leader-Williams, 2005. Mitigating human-elephant conflict outside protected areas in Africa: Crop raiding in Transmara District, Kenya. J. Applied Ecol., 42: 1175-1182.

Struhsaker, T.T., 1999. Ecology of an African Rain Forest: Logging in Kibale and the Conflict Between Conservation and Exploitation. University of Florida Press, Gainesville FL USA.

Thouless, C.R. and J. Sakwa, 1995. Shocking elephants: Fences and crop raiders in Laikipia district, Kenya. Biol. Conserv., 72: 99-107.

Tweheyo, M. and J. Obua, 2001. Feeding habits of chimpazees (Pan troglodytes), red-tailed monkeys (Cercopithecus ascanius larvatus) and blue monkeys (Thercopithecus mitis stuhhlaine) on figs around Budongo Forest Reserve, Uganda. Afr. J. Ecol., 39: 133-139.

Twheyo, M., 2003. Abundance, distribution and phenology of chimpanzee food in the Budongo Forest Reserve, Uganda. Ph.D. Thesis, Agricultural University of Norway, Oslo. 